\title{
AUTONOMIA, INTERAÇÃO, DIÁLOGO E COLABORAÇÃO: CARACTERÍSTICAS DE UM CURSO DE PEDAGOGIA A DISTÂNCIA
}

\author{
Reginaldo Fernando Carneiro*
}

\section{RESUMO}

A formação do professor em cursos de Educação a Distância cresceu muito nos últimos anos e, por isso, faz parte das discussões no âmbito educacional. Assim, neste artigo, temos como objetivo discutir algumas características - autonomia, interação, diálogo e colaboração - do curso de Pedagogia a distância da Universidade Aberta do Brasil (UAB), oferecido pela Universidade Federal de São Carlos (UFSCar), a partir de situações que ocorreram nas disciplinas relacionadas à matemática. Para tanto, realizamos uma pesquisa de natureza qualitativa, desenvolvida entre 2009 e 2012, em que utilizamos, para produção de dados, atividades virtuais e entrevistas semiestruturadas de oito professoras que haviam cursado as disciplinas de matemática. A análise evidenciou a colaboração e a negociação na atividade em que tiveram que elaborar textos coletivos. Além disso, destacou a qualidade do diálogo e a interação na perspectiva do estar junto virtual entre professoras e também com o tutor, ao tornaremse parceiros no processo de aprendizagem. Por fim, as situações explicitaram que as professoras podem ter desenvolvido a autonomia, pois, de forma individual e na relação com o outro, puderam participar ativamente da construção do conhecimento. Palavras-chave: Autonomia. Interação. Diálogo. Colaboração. Educação a Distância.

\section{ABSTRACT \\ AUTONOMY, INTERACTION, DIALOG AND COLLABORATION: CHARACTERISTICS OF A DISTANCE PEDAGOGY COURSE}

The teacher education in Distance Education courses has grown in the last few years and, therefore, has become an integral part of discussions within the educational sector. The objective of this article is to discuss some of the characteristics - autonomy, interaction, dialogue and collaboration - of the Distance Education course offered by the Open University of Brazil (UAB) at the Federal University of São Carlos (UFSCar), focusing on situations that occurred related to the instruction of mathematics. With this aim, we undertook a qualitative research study, developed between 2009 and 2012, whose data was derived from virtual activities and semi-structured interviews with eight teachers who had taken mathematics courses. The analysis revealed collaboration and negotiation during activities in which participants had to create collective texts. In addition, findings highlighted the quality of the dialogue and interaction within the perspective of the teachers being together, virtually, as well as with the tutor, thus becoming partners in the learning process. Finally, the situations emphasized that the

\footnotetext{
* Doutor em Educação pela Universidade Federal de São Carlos (UFSCar). Professor da Faculdade de Educação da Universidade Federal de Juiz de Fora (UFJF). Endereço Institucional: Faculdade de Educação, Universidade Federal de Juiz de Fora, Rua José Lourenço Kelmer, s/n, Campus Universitário, São Pedro, Juiz de Fora - MG. CEP: 36036-900. reginaldo.carneiro@ufjf.edu.br
} 
teachers may have developed autonomy because, both individually and in relationship to one another, they were able to actively participate in the creation of knowledge.

Keywords: Autonomy. Interaction. Dialogue. Collaboration. Distance Education.

\section{RESUMEN}

\section{AUTONOMÍA, INTERACCIÓN, DIÁlOGO Y COLABORACIÓN: CARACTERÍSTICAS DE UN CURSO DE PEDAGOGÍA A DISTANCIA}

La formación de profesores en cursos de Educación a Distancia ha crecido mucho en los últimos años y, por eso, hace parte de las discusiones en el ámbito educativo. Así, en este artículo, tenemos como objetivo discutir algunas características autonomía, interacción, diálogo y colaboración - del curso de Pedagogía a distancia de la Universidad Abierta de Brasil (UAB), ofrecido por la Universidad Federal de San Carlos (UFSCar), a partir de situaciones que ocurrieron en las asignaturas relacionadas a las matemáticas. Para ello se realizó una investigación de naturaleza cualitativa, desarrollada entre 2009 y 2012, la cual se utilizó para la producción de datos, actividades virtuales y entrevistas semi-estructuradas de ocho profesoras que habían cursado las asignaturas de matemática. El análisis evidenció la colaboración y la negociación en la actividad en la que tuvieron que elaborar textos colectivos. Además de eso, se destacó la cualidad del diálogo y la interacción en la perspectiva de estar juntos virtualmente entre profesoras y también con el tutor, al volverse compañeros en el proceso de aprendizaje. Por último, las situaciones evidenciaron que las profesoras pudieron haber desarrollado la autonomía, pues, de forma individual y en la relación con el otro, pudieron participar activamente de la construcción del conocimiento

Palabras clave: Autonomía. Interacción. Diálogo. Colaboración. Educación a Distancia

\section{Introdução}

A formação docente realizada em cursos na modalidade a distância vem crescendo nos últimos anos e está no foco dos debates educacionais, principalmente com relação à qualidade dessa formação. Pesquisadores dividem-se entre a defesa da Educação a Distância (EaD) e a crítica a ela.

A utilização da EaD para a formação continuada de professores em serviço, segundo Giolo (2008), é uma excelente e importante iniciativa, mas não se pode trocar a formação inicial presencial pela formação a distância e substituir a formação que acontece na sala de aula por outra, descolada dos espaços tradicionais de ensino e aprendizagem, que são: a escola e a universidade.

Não se estão formando professores para atuar na docência a distância, mas na docência presencial, e, por isso, são importantes, ainda segundo esse autor
(GIOLO, 2008, p. 1228), as aprendizagens que ocorrem "na prática da convivência, na experimentação, nas cobranças mútuas, nos laboratórios, nos seminários, nas palestras, nos debates temáticos, nas apresentações culturais, nos estágios supervisionados, nas falas de sala de aula, dos corredores, do restaurante universitário etc.".

Contrapondo-se a esses argumentos, de acordo com Moon (2008), há um grave problema educacional de dimensão mundial: a escassez de professores. Por esse motivo, muitos países estão contratando professores leigos para lecionar, principalmente no ensino primário. Devido à necessidade de formar esses docentes, uma alternativa é a educação aberta e a distância, pois essa modalidade de formação permite que eles não se afastem de suas salas de aulas.

No entanto, para que isso aconteça, é necessário rever algumas concepções, como a perspectiva de 
que a EaD é uma melhor segunda opção, ou seja, uma alternativa às pessoas que não podem cursar universidades de excelência. "Essa mudança é necessária não apenas porque, em muitos setores, existem poucas alternativas, mas também porque, em termos de qualidade, eficiência e sustentabilidade, as novas formas de programas abertos e a distância têm uma melhor relação custo-benefício" (MOON, 2008, p. 803-804).

Dessa forma, não há unanimidade nos posicionamentos dos pesquisadores da área, e isso sinaliza a importância de pesquisas sobre a formação de professores em EaD. Assim, neste artigo, recorte da pesquisa de doutorado do autor (CARNEIRO, 2012), propomos uma discussão sobre algumas características - autonomia, interação, diálogo e colaboração - do curso de Pedagogia a distância da Universidade Aberta do Brasil (UAB), oferecido pela Universidade Federal de São Carlos (UFSCar), a partir de situações ocorridas nas disciplinas relacionadas à matemática.

Para tanto, inicialmente, discutiremos essas características, que embasam teoricamente o texto. Depois, apresentaremos uma discussão sobre a pesquisa qualitativa desenvolvida. Em seguida, exporemos e analisaremos algumas situações ocorridas no curso de Pedagogia a distância, que evidenciam essas características; e, por fim, teceremos algumas considerações.

\section{Características de um curso a distância}

Borba, Malheiros e Zulatto (2007) propõem um tripé em que devem estar pautados os cursos em EaD: a interação, o diálogo e a colaboração. Segundo os autores, essas características condicionam a natureza da aprendizagem e, por isso, influenciam na qualidade dos cursos.

Acrescentamos a esse tripé a autonomia como outro elemento da EaD que vem sendo evidenciado pela literatura da área e que é fundamental nessa modalidade de educação. Apenas para efeito didático, discutiremos essas características separadamente, compreendendo, porém, que elas estão inter-relacionadas.

A primeira característica que abordaremos é a autonomia, que, segundo Preti (2005, p. 113), não pode ser confundida com liberdade sem interferências, pois trata-se de um processo individual, mas também permeado pelo outro, pelo professor, pela escola, que, "mesmo quando propõem desenvolver ação emancipatória em relação ao cidadão, ao educando, acabam exercendo algum tipo de influência, apontando a direção, produzindo valores e significados". Assim, o indivíduo não é o único responsável por desenvolver sua autonomia, mas pode assumir uma posição ativa, participante e consciente quando está nesse processo, que se constitui "de relações e inter-relações, em que as dimensões política e afetiva, além das dimensões cognitivas e metacognitivas, se fazem presentes" (PRETI, 2005, p. 139).

Preti (2005, p. 120) ainda destaca que o desenvolvimento da autonomia é um processo inacabado e deve ser constantemente construído, por isso, é "capacidade de desenvolver independência nas situações cognitivas, de tomar consciência e superar conflitos cognitivos, de desenvolver atitude metacognitiva, isto é, aprendizagem autônoma". Assim, não é sinônimo de autodidatismo, pois este é compreendido como o fato de a pessoa estudar por conta própria.

Nessa mesma perspectiva, Belloni (2003) compreende aprendizagem autônoma como sendo o processo de ensino e aprendizagem que tem como foco o estudante e deve considerar suas experiências. Assim, o professor auxilia o aluno, que é "gestor de seu processo de aprendizagem, capaz de autodirigir e autorregular esse processo" (BELLONI, 2003, p. 40).

No entanto, essa autora destaca que ainda é raro, nos cursos de EaD, esse estudante autônomo, e a maioria participa passivamente do seu processo de aprendizagem. Muitos estudantes têm dificuldades em se adequar à $\mathrm{EaD}$, devido às exigências da aprendizagem autônoma, como a organização do tempo e dos estudos, pois não há um professor exigindo que os alunos estudem, façam as tarefas, leiam os textos etc. Isso provoca neles problemas de motivação, pois pensam que são despreparados, incapazes, e culpam-se pelo seu insucesso (BELLONI, 2003).

Compreendemos que isso pode acontecer em razão da educação presencial, modalidade em que a maioria dos alunos teve sua experiência escolar 
e na qual permaneceram durante toda sua vida, com passividade constante, ou seja, para aprender, o aluno tinha que repetir, copiar, memorizar, obedecer e não questionar. Um grande desafio da EaD é proporcionar condições para que o estudante torne-se autônomo.

Outro aspecto importante da EaD é a interação, que entendemos como sendo o processo de comunicações e diálogos que ocorrem no Ambiente Virtual de Aprendizagem (AVA), envolvendo os alunos, os tutores e os professores. O teor dessas interações pode referir-se aos conteúdos e aos temas estudados; às dúvidas quanto à forma de realizar uma atividade ou utilizar uma ferramenta; a um problema de acesso; a uma solicitação de maior flexibilidade no prazo de entrega da atividade; às discussões realizadas, além de outros aspectos.

Os estudantes, por estarem distantes espacialmente e temporalmente, sentem-se isolados e sozinhos. Dessa forma, a interação intensa entre eles (e o tutor) é muito importante, diferenciando qualitativamente a natureza da aprendizagem: "a ausência física do professor é compensada por uma comunicação intensa, que limita a possibilidade do aluno se sentir sozinho, isolado" (BORBA; MALHEIROS; ZULATTO, 2007, p. 26).

Em seus estudos, Valente $(2003,2011)$ discute algumas possibilidades pedagógicas que podem estar presentes nos programas de $\mathrm{EaD}$ e que determinam o tipo de interação existente. E ressalta que a intervenção docente é fundamental, pois "é intermediada por uma tecnologia e não existem os gestos, o olho no olho, os elementos usados em situações presenciais que o aprendiz pode usar para compensar certas deficiências de comunicação" (VALENTE, 2003, p. 140).

Valente (2011) assinala que as abordagens discutidas em suas investigações dependem do nível de interação, que varia em um contínuo: em um extremo está a broadcast e, em outro, o estar junto virtual, mas há também uma abordagem intermediária denominada de virtualização da escola.

Segundo esse autor, a abordagem broadcast possibilita a organização e a disseminação da informação para os estudantes por meio de diferentes tecnologias - material impresso, rádio, TV, CD-ROM e Internet -, mas o professor não tem nenhum contato com os estudantes e, por isso, não recebe nenhum retorno. Assim, não há nenhum tipo de interação entre professor-aluno e tampouco entre os alunos, por isso, não é possível saber se o estudante está apenas memorizando ou construindo conhecimento. Nesses moldes, o aluno é o responsável por transformar as informações que recebe em conhecimento (VALENTE, 2003).

A última abordagem proposta por Valente (2003) é o estar junto virtual. Requer o acompanhamento e o assessoramento de perto pelo professor, de forma a conhecer seus estudantes, com objetivo de propor desafios e ajudá-los a atribuir significados ao que estão aprendendo, para que consigam selecionar e processar as informações, transformá-las, aplicá-las, buscando novas informações que sejam necessárias para construir seus próprios conhecimentos. A interação é intensa e ocorre tanto entre aluno e professor como entre os estudantes em atividades síncronas e assíncronas.

A abordagem denominada virtualização da escola pretende transferir para um ambiente tecnológico as mesmas características da sala de aula tradicional, em que o professor é o centro do processo de ensino e aprendizagem e transmite as informações para os estudantes, que podem transformá-las em conhecimento ou apenas memorizá-las. Existe um mínimo de interação entre professor e aluno, mas, na maioria das vezes, não suficiente para a construção de conhecimento, pois "resume-se em verificar se o aprendiz memorizou a informação fornecida, por meio de uma avaliação do tipo teste ou ainda de uma aplicação direta da informação fornecida em um domínio muito restrito" (VALENTE, 2003, p. 141).

O diálogo ou a comunicação é outro componente que faz parte da $\mathrm{EaD}$, e é perpassado pela escrita, que pode ser considerada, se não a única, a forma mais utilizada de comunicação entre os estudantes e entre professor, tutor e estudantes. Nos cursos a distância, a maioria das atividades - as produções de texto, as discussões em fóruns, em chats, as trocas de mensagens eletrônicas por e-mail, as avaliações - é baseada na escrita.

Dessa forma, observamos a grande importância da escrita na EaD, e Tancredi, Reali e Mizukami (2005, p. 36) assim se expressam com relação a ela: 
[...] a comunicação que se estabelece on-line retoma o paradigma da escrita, que estava de certa forma abandonado como meio de comunicação interpessoal dado o advento e a rapidez proporcionados pelo uso do telefone, por exemplo. Com o uso da internet professores e alunos - assim como todos os demais usuários - têm a possibilidade de utilizar a escrita para se comunicar: produzir, expor suas ideias, escrever, reescrever, ler, reler, atribuir significado [...]

Um importante diferencial com relação à escrita que se ensina e se aprende na escola é o significado do ato de ler e escrever e o fazer e refazer continuamente para que o outro apreenda a mensagem de forma fiel.

Para AlrØ e Skovsmose (2006, p. 29), o diálogo "é visto como um processo de descoberta, influenciado pelo fazer coletivo e compartilhado, não se constituindo como mero ato das pessoas se comunicarem, mas da profundidade e riqueza desse ato". Assim, a qualidade da aprendizagem está intimamente ligada à qualidade do diálogo e à clareza das mensagens trocadas.

Esse, segundo Mill et al. (2008), é um aspecto-chave, pois entre a emissão da mensagem e o seu recebimento há um tempo físico, o que dificulta o esclarecimento de ambiguidades na mensagem. $\mathrm{Ou}$ seja, a mensagem precisa estar clara, de forma que o receptor possa compreender exatamente o que o emissor tentou escrever, explicar, orientar etc., pois uma mensagem mal interpretada pode causar grandes problemas nas relações que se estabelecem no AVA.

Dessa forma, Palloff e Pratt (2007) ressaltam que a impossibilidade dos contextos visual e verbal na $\mathrm{EaD}$, que estão presentes na comunicação face a face, pode ser tanto benéfica como prejudicial, pois a comunicação escrita é um equalizador que pode, de certa forma, dar uma sensação de anonimato, levando a refletir mais antes de dizer algo ou a libertar-se para dizer coisas que não seriam ditas pessoalmente.

A colaboração é também uma característica importante, que deve estar presente na $\mathrm{EaD}$ e, segundo Borba, Malheiros e Zulatto (2007), possibilita a participação ativa no processo de ensino e aprendizagem em que professores e alunos são parceiros e assumem papéis de protagonistas, em que todos ensinam, aprendem e produzem conhe- cimento. Essa forma de participação exige que as atividades sejam realizadas coletivamente, de forma que as tarefas que cada um executa sejam complementares, para atingir objetivos comuns.

Assim, a colaboração pode auxiliar a minimizar os sentimentos de isolamento e solidão despertados pela $\mathrm{EaD}$, pois a interação entre os atores, que ocorre normalmente por meio da escrita na tela do computador, conecta todos os envolvidos a partir das atividades e da promoção da interdependência (PALLOFF; PRATT, 2007).

Ainda, de acordo com essas autoras, na colaboração há o desenvolvimento da criatividade, do pensamento crítico e do diálogo. Os estudantes têm a oportunidade de ampliar e de aprofundar suas experiências de aprendizagem, testar novas ideias ao compartilhá-las com o grupo, além de receber feedbacks críticos e construtivos. Dessa forma, "a aquisição colaborativa de conhecimento é chave para o sucesso da criação de ambientes de aprendizagem virtual. Atividades que requerem a interação entre os alunos e incentivam a partilha de ideias promove um nível profundo de pensamento" (PALLOFF; PRATT, 2007, p. 158).

A discussão sobre essas características dos cursos de EaD indica que elas podem ser o diferencial no que concerne à qualidade de um curso e têm impacto no processo de ensino e aprendizagem nessa modalidade educacional.

\section{Os caminhos da pesquisa...}

Na perspectiva de Fiorentini e Lorenzato (2006, p. 60), a pesquisa é "[...] um processo de estudo que consiste na busca disciplinada/metódica de saberes ou compreensões acerca de um fenômeno, problema ou questão da realidade ou presente na literatura o qual inquieta/instiga o pesquisador perante o que se sabe ou diz a respeito".

Dessa forma, com o objetivo de discutir algumas dessas características - autonomia, interação, diálogo e colaboração - no curso de Pedagogia a distância da UAB-UFSCar, a partir de situações que ocorreram nas disciplinas relacionadas à matemática, optamos por desenvolver uma pesquisa qualitativa (BOGDAN; BIKLEN, 1994; LÜDKE; ANDRÉ, 1986). 
Participaram da investigação oito professoras que haviam cursado as disciplinas Linguagens Matemática 1 (LM1) e Linguagens Matemática 2 (LM2) desse curso. À época do estudo, elas eram professoras da Educação Infantil e/ou dos anos iniciais do Ensino Fundamental: tinham o magistério de nível médio e estavam cursando o ensino superior. Elas escolheram o nome pelo qual seriam identificadas na pesquisa; algumas preferiram um nome fictício e outras optaram pelo seu próprio nome: Alice, Ana, Andréia, Branca, Kerusca, Lusmarina, Renata e $\mathrm{Su}$.

Selecionamos para participação apenas professoras que, portanto, já tinham o contato com a sala de aula em que ensinavam os conteúdos matemáticos e eram licenciandas no curso de Pedagogia, porque tínhamos como hipótese que os processos formativos possibilitados pelas disciplinas que envolviam conteúdos matemáticos poderiam contribuir para a aprendizagem desses conteúdos, assim como para a aprendizagem da docência, a partir da reflexão teórica sobre suas práticas e, consequentemente, para seu desenvolvimento profissional docente.

As disciplinas LM1 e LM2 tiveram como objetivos possibilitar aos alunos conhecer e analisar a realidade escolar com relação aos processos de ensinar e aprender matemática e o que a influencia; caracterizar e analisar a situação do ensino de matemática nos anos iniciais do Ensino Fundamental; e conhecer e analisar alternativas metodológicas do ensino de matemática que considerem a realidade escolar desse nível de ensino. Essas disciplinas foram objeto de estudo, pois buscamos, na pesquisa de doutorado, investigar processos formativos em matemática de professoras dos Anos Iniciais em um curso a distância de Pedagogia.

Nesta pesquisa, foram utilizadas como fonte para produção de dados as atividades virtuais realizadas pelas professoras nas disciplinas mencionadas anteriormente, assim como entrevistas semiestruturadas para esclarecer pontos obscuros dessas atividades. A coleta foi realizada no período de agosto de 2010 a julho de 2011.

As questões presentes na entrevista buscavam apreender as percepções sobre as disciplinas, a influência do ambiente virtual em suas aprendizagens, as vivências das professoras nas disciplinas, identificar aprendizagens, dificuldades e possíveis soluções, saber sobre os conteúdos matemáticos abordados etc. Assim, buscamos, por exemplo, tirar dúvidas sobre mensagens postadas por elas em fóruns ou sobre como resolveram uma atividade matemática, obter informações sobre os diferentes tipos de ferramentas utilizadas no ambiente, sobre o modelo do curso etc.

A entrevista permite "correções, esclarecimentos e adaptações que a tornam sobremaneira eficaz na obtenção das informações desejadas" (LÜDKE; ANDRÉ, 1986, p. 34). Além disso, possibilita o aprofundamento de pontos levantados por outras técnicas, como as atividades realizadas nas disciplinas.

Os excertos das professoras, apresentados neste texto, são identificados com o nome da participante e recebem a indicação do tipo de atividade a que se refere o trecho: fórum de discussão, iniciais da disciplina - LM1, LM2 - ou entrevista. Para a análise de dados, pautamo-nos na teoria de análise de conteúdo de Bardin (1977, p. 44), que se refere a "um conjunto de técnicas de análise de comunicações visando obter por procedimentos sistemáticos e objectivos de descrição do conteúdo das mensagens indicadores que permitam a inferência de conhecimentos relativos às condições de produção/ recepção destas mensagens".

Segundo Fiorentini e Lorenzato (2006, p. 133), a análise é "um processo trabalhoso e meticuloso que implica múltiplas leituras do material disponível, tentando nele buscar unidades de significação ou, então, padrões e regularidades para, depois, agrupá-las em categorias". É o momento de organização e reflexão sistemática, com o intuito de compreender o fenômeno estudado, e exige um esforço do investigador no sentido de se debruçar sobre os dados durante certo período de tempo, realizar várias leituras do material, ir dos dados ao referencial teórico e voltar do referencial aos dados.

Optamos, na pesquisa, pela análise a partir da unidade de registro "tema" e procedemos à categorização, que consistiu na classificação por analogia dos elementos, de maneira a formar um conjunto de dados, agrupando as mensagens a partir de critérios predeterminados. Focamos no aspecto semântico, ou seja, partimos de categorias temáticas, que 
emergiram das muitas aproximações com relação a diversos temas.

A partir do exposto, faremos agora uma discussão sobre situações ocorridas nas disciplinas de matemática do curso de Pedagogia a distância da UAB-UFSCar, que evidenciam a autonomia, a interação, o diálogo e a colaboração.

\section{Situações ocorridas nas disciplinas}

Para desenvolver autonomia, interação, diálogo e colaboração, é necessário pensar na concepção de um curso a distância. Dessa forma, não é suficiente, ainda que fundamental, que o professor das disciplinas busque, de alguma forma, promover esse desenvolvimento.

No curso de Pedagogia a distância da UAB-UFSCar, o tutor virtual assume a função docente, e sua formação deve estar de acordo com a disciplina em que irá atuar. Ele precisa estar em permanente contato com o aluno, auxiliando-o a realizar as atividades da disciplina, discutindo sobre o conteúdo, avaliando, orientando na solução de dificuldades e/ ou indicando com quem ele deve entrar em contato para isso. Para tanto, o tutor participa de um curso de formação com carga horária de 120 horas, em que aprende sobre etiqueta na Internet, a utilização do AVA, feedbacks, entre outros aspectos.

Além disso, no curso de que tratamos aqui, cada tutor era responsável por, no máximo, 25 estudantes em uma disciplina, o que possibilitava que ele acompanhasse individualmente esses alunos, podendo estar junto virtualmente. Em outros cursos da UAB, o tutor acompanha ou um grupo de estudantes em todas as disciplinas que ocorrem simultaneamente ou um grupo maior, às vezes com 100 alunos ou mais, em uma única disciplina.

Além disso, as dúvidas dos estudantes deviam ser respondidas pelo tutor em um prazo de 24 horas, no caso de serem urgentes, e em 48 horas em outros casos; por isso, havia a necessidade de o tutor acessar o ambiente virtual diariamente. Esses aspectos possibilitavam uma constante relação entre tutor e seus alunos, de forma a dar um movimento dinâmico às disciplinas, pois os estudantes precisavam de apoio nos mais diferentes âmbitos, para que não se sentissem desmotivados e sozinhos.
Também era solicitado aos tutores que participassem efetivamente das discussões, propondo questionamentos que levassem a reflexões sobre os conteúdos, incentivassem a participação dos estudantes, tirassem dúvidas, entre outras atribuições.

Especificamente nas disciplinas LM1 e LM2, a professora responsável dividia os tutores em duplas que trabalhavam juntos, sempre tentando agrupar um pedagogo e um professor de matemática, para que trocassem ideias e compartilhassem suas experiências. Ainda, o material utilizado nas disciplinas era elaborado pelos próprios professores, que tinham o cuidado de focar a formação de professores, objetivo do curso.

Passamos agora a discutir algumas situações vividas pelos participantes da pesquisa nas atividades. No excerto a seguir, da entrevista de Renata, podemos verificar a interação e a colaboração entre os estudantes. Ela apontou que a elaboração coletiva de textos na wiki ${ }^{1}$ deve ser apoiada por um fórum de discussão no qual serão propostas e discutidas as ideias para a construção do texto.

Sem dizer que é um exercício de compreensão da ideia do outro. [...] proporciona um espaço mais acadêmico, em que normas são mais rígidas e que nos aproximam de uma forma de escrever o que se compreende com bases teóricas sólidas. Caso o que se colocou não esteja em consonância com o assunto tratado anteriormente e posteriormente, há uma desarmonia perceptível e, consequentemente, uma reconstrução do que se aprendeu. (Renata, Entrevista).

A elaboração de um texto coletivo possibilita o envolvimento dos diferentes membros de um grupo. Entretanto, esse grupo não pode ser composto por muitas pessoas, para que não haja argumentos muito distintos, o que tornaria difícil a concatenação das ideias de todos. Além disso, a escrita a várias mãos exige um cuidado especial, ao modificar as ideias do outro, não apenas pelo fato de o colega não gostar, mas também porque o autor das mudanças pode haver entendido de forma equivocada o que o outro escreveu.

É fundamental, nessa atividade, a participação de todos os membros do grupo; caso contrário, a discussão ficará empobrecida, pois não contará com

\footnotetext{
1 Essa ferramenta possibilita a construção de um texto coletivo por diversos estudantes e registra as modificações realizadas por cada um deles.
} 
uma gama de argumentos, oriundos dos diferentes pontos de vista e opiniões. Por isso também, a importância de um fórum de discussão simultâneo, em que os participantes podem discutir as ideias, levantar os aspectos do texto que não compreenderam, confrontar as opiniões do outro que parecem não estar em consonância com o objetivo do texto.

Dessa forma, a wiki possibilita a interação mais efetiva entre os participantes e promove a colaboração. Palloff e Pratt (2007) discutem que essa ferramenta pode auxiliar os estudantes a propor novas ideias e compartilhá-las com o grupo, o qual pode fornecer um retorno, baseado em argumentos sólidos sobre essas ideias, no sentido de aceitação ou recusa, para que o autor da proposta reveja sua posição.

Nesse contexto, Notari (2006, p. 132) ressalta a importância da negociação com os colegas, para que haja a formulação de sua própria opinião sobre o assunto, a consciência de suas opiniões pessoais, o que conduzirá “a construção de outro conceito, mais preciso do objeto tratado". Assim, essa negociação pode ocorrer, como apontado por Renata, em um fórum de discussão concomitante à produção do texto. Para que ocorra essa negociação, o grupo precisa apresentar maturidade para aceitar a colaboração do outro e estabelecer um clima de respeito mútuo, de confiança e de diálogo.

Os fóruns de discussão potencializaram o diálogo entre estudantes e entre eles e o tutor/professor. Esse espaço de diálogo constituiu-se também de um ambiente de reflexão, de argumentação, de elaboração do pensamento, de exposição de opiniões etc.

Andréia considerou que os fóruns de discussão eram espaços de aprendizagem, mas, para que isso, de fato, acontecesse, foi fundamental o acompanhamento de perto pelo tutor e também pelo professor da disciplina. Nessa direção, segundo Su, para que ocorra aprendizagem, é preciso participação dos tutores, indicando os caminhos e

[...] fazendo novos questionamentos daquilo que os alunos não estão desenvolvendo de acordo com as leituras. Pois só na nota que é falado sobre o nosso desempenho, assim fica vaga a discussão. E muitas vezes o fórum se torna pobre em discussões. ( $\mathrm{Su}$, Entrevista).

A possibilidade de todos visualizarem as mensagens do fórum de discussão é um potencial da
EaD e dos AVA, pois permite a retomada de uma postagem no fórum para uma discussão posterior, ou seja, a escrita como principal forma de diálogo e comunicação apresenta-nos alguns aspectos importantes, que não ocorrem na sala de aula presencial, em que se privilegia a linguagem verbal.

Esse espaço proporcionado pelo AVA pode tornar-se ainda mais potencializador de aprendizagens do que uma sala de aula, porque, além de as participações ficarem registradas, como já discutido, todos os estudantes precisam envolver-se e participar da atividade, o que pode não acontecer na sala de aula presencial, quando os alunos estão presentes, mas nem sempre tomam parte nas discussões.

Isso pode ocorrer quando são propostos questionamentos, argumentações, relações entre os conteúdos da postagem de um colega e o referencial, e não quando há uma participação camuflada, quando um estudante posta, no fórum de discussão, mensagens superficiais, apenas concordando com a opinião do colega ou trazendo um excerto do referencial teórico. Por exemplo, no trecho abaixo, de um fórum para discussão da resolução de problemas sobre fração, Su comentou a postagem de uma colega, relacionando-a com o referencial estudado, em que ela utiliza para a resolução as frações equivalentes, e não o mínimo múltiplo comum (m.m.c).

Olá Aluna 14 !!!!

Esse problema você resolveu fazendo o MMC e eu utilizando as frações equivalentes. Mas se eu simplificar os $6 / 8$ vai dar $3 / 4$. Realmente é como a tutora falou o que precisamos na resolução dos problemas é a nossa justificativa de como resolvemos.

\section{Abs}

$\mathrm{Su}$ (Fórum de discussão, LM2).

Segundo Batista e Gobara (2007), o fórum, por si só, não possibilita a interação entre os participantes; é preciso que ocorra, nas atividades, a participação intencional de tutores e alunos, com o objetivo de promover a aprendizagem. Concordamos com as autoras e destacamos a importância da mediação do tutor, dirigindo e orientando os estudantes para que possam construir conhecimento. Nesse sentido, é crucial sua participação efetiva durante o fórum de discussão, propondo questionamentos, discutindo as ideias apresentadas, sintetizando as 
opiniões dos alunos, de forma a auxiliá-los em suas aprendizagens.

Nos trechos a seguir, também retirados do fórum sobre a resolução de problemas de fração, Alice apresentou algumas dúvidas com relação à maneira como um colega os resolveu.

Alice: Olá Tutor 1, não realizei completamente a leitura do material, não sei se estou certa, mas como estou somando frações (exercício 1 e demais) resolvê-las através de desenho, e faria também o cálculo reduzindo as frações ao mesmo denominador, será que estou certa? Não compreendi bem a explicação do Aluno 2, estou retornando a leitura, pra sanar dúvidas.

Aluno 2: Olá Alice e colegas!

A maneira como resolvi as questões foi simplesmente seguindo o material impresso; procurei trabalhar o mais simples possível imaginando estar passando essa atividade em uma sala de aula para as crianças.

Segue anexa a resolução dos exercícios, tentei colar aqui as figuras e/ou desenhos, não sei por que cargas d'agua não consegui fazê-lo. (Fórum de discussão, LM2)

Nessa interação, o tutor questionou como os alunos estavam resolvendo os problemas e apontou a importância da explicação do Aluno 2 para ajudar os outros a pensarem e interpretarem as situações-problema. Esse questionamento fez com que Alice expusesse a forma como estava pensando. Fica evidente, neste excerto, a importância do outro na aprendizagem de Alice, pois foi estabelecido um diálogo no sentido de fazer com que ela compreendesse o processo utilizado pelo Aluno 2 na resolução do problema. A explicação do aluno fez com que ela percebesse que não havia compreendido bem as ideias presentes no material de estudo, o que a fez retomá-lo para nova leitura.

Ao postar a resolução da atividade, o Aluno 2 teve apenas o objetivo de expor para o tutor e os colegas a estratégia que havia utilizado e, por isso, a priori, não é possível prever as interações que ocorrerão, ou seja, é a partir da interação e do diálogo, inicialmente, sem maiores pretensões que vão se tecendo redes de colaboração.

Ainda sobre essa atividade, Kerusca tentou confrontar suas respostas com as dos colegas, buscando informações para saber se estava no caminho certo.
Alguns colegas responderam ao questionamento da professora. Assim, o fórum de discussão possibilitou compararem as soluções e também descreverem as estratégias usadas.

Kerusca: [...] eu achei o mesmo resultado em todos os problemas, mas não consigo resolvê-los de maneiras diferentes, se for por desenho, ou por resolução comum, são da mesma forma.

Vocês encontraram os mesmos pontos? (Fórum de discussão, LM2)

Além disso, no fórum de discussão sobre os conteúdos de geometria na disciplina de LM2, Ana disponibilizou sites em que podiam ser encontradas obras de artes para ensinar matemática, assim como um arquivo com obras de Tarsila do Amaral, corroborando a afirmação feita por ela de que os alunos podem fazer conexões da matemática com outras áreas do conhecimento, ao explorarem obras de arte, pinturas, desenhos, esculturas etc.

Segue em ANEXO exemplos de obras da Tarsila do Amaral que podem ser trabalhadas na sala de aula com as crianças, como as figuras bidimensionais e tridimensionais, situações-problema, tamanho original da obra, área e perímetro, etc.

Além disso, o professor poderá trabalhar a biografia da autora, textos sobre o movimento cubista (Língua Portuguesa e História), entre outras situações.

www.suapesquisa.com/artesliteratura/cubismo/

www.google.com.br/imagens

Ana (Fórum de discussão, LM2).

Da mesma forma, Alice apresentou, no fórum em que discutiram sobre o pensamento estocástico, também em LM2, um site que abordava assuntos relacionados à estatística.

Olá pessoal, tudo bem?

E quando falamos em estatística relacionada à educação? Quais assuntos podemos tratar? Separei uma matéria do jornal O Globo sobre a desigualdade de acesso entre negros e brancos à escola, se tiverem um tempinho deem uma olhada: http://oglobo.globo. com/politica/educacao-ainda-desigual-para-negros-brancos-2950802

Alice (Fórum de discussão, LM2).

$\mathrm{O}$ fórum configurou-se como um ambiente em que as professoras puderam compartilhar suas dúvi- 
das, estratégias de resolução, ideias e experiências de sala de aula, fato que enriqueceu muito as discussões. Esses trechos permitem compreender que o fórum não se limita às discussões baseadas nas ideias presentes no material estudado, mas extrapolam, mostrando outras relações que as professoras fazem com a prática de sala de aula ou ainda com reportagens encontradas na Internet.

Essas interações e as mediações do tutor podem desencadear sentimentos positivos - elevação da autoestima e valorização - e também negativos, como isolamento e desmotivação, que são capazes de influenciar a continuidade da participação das professoras nas discussões. A partir dessas afirmações, é preciso reiterar o quanto é fundamental que os tutores façam constantemente uma leitura atenta e cuidadosa das mensagens postadas nos fóruns, no sentido de retomar ideias, colocar questionamentos, propor reflexões, explicitar suas opiniões e sugerir que os outros estudantes leiam os textos indicados.

Além disso, as interações que aconteceram nos fóruns possibilitaram minimizar a distância espacial entre os participantes, pois as professoras expuseram sentimentos, emoções e acontecimentos de suas vidas particulares, podendo ajudar a diminuir o isolamento apontado pela literatura da área, que acontece na EaD.

As professoras fortaleceram os laços afetivos, a partir das relações que estabeleceram entre si nos fóruns, como o sentimento de pertencimento a um grupo, a uma turma. Por exemplo, no início da mensagem de Renata, em um fórum de LM2, ao referir-se a uma expressão utilizada por uma colega: "Plagiando nossa colega de turma Aluna 15 , já virando abóbora vou pontuar algumas questões" (Renata, Fórum de discussão, LM2, grifo da professora). Esses aspectos podem aproximar os alunos, mesmo à distância, fazendo com que se sintam acolhidos, ouvidos, fazendo parte de um grupo. Renata utiliza a expressão "virando abóbora" para se referir ao horário em que se comunicava com o grupo, que normalmente ocorria próximo da meia-noite.

Lusmarina, em vários momentos, postou mensagens que auxiliaram os colegas na compreensão de ideias. Em uma delas, expôs no fórum, que teve como objetivo discutir a matemática na constituição da cidadania a partir de uma citação presente no material estudado, sua compreensão sobre alguns aspectos presentes nesse material, e colegas de curso destacaram a importância dessa troca de experiências entre as que já são professoras e aqueles que ainda não têm a vivência de sala de aula.

Lusmarina: Olá Aluna 8 e Aluna 9!

Que bom, que a partir da situação real que coloquei, ficou um pouco mais claro pra vocês o entendimento da citação. Obrigada Aluna 8 pelo carinho, estou sempre tentando, se decidimos ser professor, teremos que fazer o melhor que pudermos não é mesmo? Concordo com você Aluna 9, quando coloca sobre a importância do fórum, das nossas discussões e do quanto aprendemos também com os nossos colegas. Pra mim essa atividade é a que faço com mais prazer, me dá a sensação de que estou conversando com vocês.

Abraços,

Lusmarina (Fórum de discussão, LM2).

Os comentários de Lusmarina, segundo as alunas, são importantes porque permitiram que elas compreendessem as ideias presentes no material impresso e nas discussões. Além disso, a Aluna 9 destacou como o fórum pode promover aprendizagens a partir das trocas de experiências que ocorrem por meio das mensagens postadas. Esse diálogo expressa de forma clara o que pensa a professora sobre essa atividade. Ela ressalta que parece estar conversando com as colegas, mesmo à distância.

O compartilhar de ideias presentes nesse trecho apenas ocorreu devido ao trabalho coletivo, ou seja, a colaboração entre os membros do grupo, pois, se a postagem de Lusmarina não tivesse sido retomada pelas colegas, seu conteúdo não teria sido o catalisador dessa discussão. Essa interação também favoreceu a reflexão sobre a teoria apresentada no material impresso, em que a ideia presente na citação é ampliada pela relação que Lusmarina faz com sua experiência docente.

Por fim, exporemos duas situações em que a professora e o tutor tornaram-se protagonistas, parceiros, no processo de aprendizagem da primeira. No primeiro excerto, Branca sentiu-se insegura por não saber como proceder e solicitou a ajuda dos tutores no fórum de dúvidas da atividade em que deveria fazer uma síntese das ideias presentes na unidade sobre o sistema de numeração decimal e as 
operações, e elaborar situações que envolvessem as ideias implícitas nas operações - adição, subtração, multiplicação e divisão.

Branca: Olá tutores, fiz a leitura do material, confesso que para mim não é muito fácil dizer o que compreendi sobre o texto em outras palavras, por exemplo, porque acho a linguagem matemática muito complexa, não sei se produzirei um texto de qualidade, porque não sei se vou conseguir exemplificar as operações, por isso segundo a comanda 'exemplificar com contextos em que cada uma das operações estão presentes', me deixou um pouco insegura. Como devo fazer isso, devo escrever situações-problema? Ou não?

Tutor 3: Olá Branca,

A elaboração de situações-problema pode facilitar sua compreensão das ideias das operações e, por isso, sugerimos a elaboração de pelo menos um problema para cada operação.

Com relação a sua insegurança, pensamos que se deve ao fato de ser o primeiro contato com a linguagem matemática, mas que você vai se sair bem.

Faça uma síntese das características do sistema de numeração e das propriedades de cada operação, depois procure elaborar os problemas baseando-se nos exemplos do material.

Abs

Tutor 3

Branca: Muito obrigada, pela ajuda.

Elaborei umas situações-problema com base no material impresso. Inclusive devo confessar que elaborar os problemas me ajudaram a entender melhor os diferentes tipos de situações-problema dentro de cada operação.

Não sei se elaborei um texto muito bom, talvez deveria ter sido mais objetiva, mas compreendi com mais clareza o conteúdo depois de ter que sintetizá-lo.

Respeitosamente,

\section{Branca}

Branca, ao colocar suas dúvidas e preocupações, mostrou-se aberta e expôs suas dificuldades com relação à matemática, dando parâmetros ao tutor de como interagir naquela situação. Uma qualidade da $\mathrm{EaD}$ é que as respostas não precisam ser imediatas, o que permitiu, neste caso, que o tutor tivesse tempo para refletir sobre a melhor maneira de mediar aquela situação, pois, como apontam Mill et al. (2008), é seu papel auxiliar os estudantes a sanar dúvidas e orientar-lhes as produções, diferentemente do que ocorre na maioria das situações na sala de aula presencial, em que, via de regra, as respostas devem ser imediatas.

$\mathrm{O}$ segundo excerto refere-se à atividade em que as professoras tinham que discutir sobre o jogo Avançando com o resto. ${ }^{2} \mathrm{Su}$ conversou com seu tutor sobre o que aconteceria se a ficha de um jogador caísse na casa do tabuleiro que contém o número zero:

Su: Olá Tutor 5!!!!

Analisando o jogo se eu cair na casa 0 , o que faço?

Abraços

$\mathrm{Su}$

Tutor 5: Olá, $\mathrm{Su}$, vou te ajudar, mas penso que tens condições de responder. Ao cair na casa 0 (zero) e tirar, por exemplo 2, no dado, teremos: $0: 2=0$

Se tirarmos outra quantidade no dado, como fica? Há mudança?

Abraços

Tutor 5

Su: Olá Tutor 5!!!

Entendi que quando eu cair na casa 0 (zero) independente do número que eu tirar no dado vai dar zero. Mas e ai como fica o jogo? Paro de jogar? Ou volta a jogar novamente do início? Essa é a minha dúvida a respeito do jogo.

Tutor 5: Se, independente da quantidade que você vai tirar no dado, o resultado será sempre zero, significa que não vais mais andar, está presa... acaba o jogo pra você! É uma pena, mas é o que ocorre! As crianças adoram!

Abraços

Tutor 5 (Fórum de discussão, LM1).

$\mathrm{Na}$ conversa com seu tutor, Su referiu-se a uma casa que coloca o jogador fora do jogo e à

2 Jogo de tabuleiro em que, nas casas, há diferentes números e é jogado por duas equipes alternadamente: cada equipe na sua vez joga o dado e constrói uma divisão, na qual o dividendo é o número da casa onde está sua ficha, e o divisor, o número que sai no dado. $\mathrm{O}$ resto da divisão indica por quantas casas o jogador irá movimentar sua ficha. 
justificativa deste fato, ou seja, a ficha, ao cair na casa zero, elimina o jogador, visto que, ao dividir zero pelo número que sair no dado, o resultado será sempre zero.

Podemos verificar, nessa mediação, que o tutor não dá a Su uma resposta pronta, mas, ao propor uma jogada hipotética e questioná-la sobre o que iria ocorrer, ele a instiga, motivando-a a chegar à conclusão sozinha. Aqui observamos a importância do tutor que leva a professora a investigar e também a validar suas respostas, pois, ao chegar à conclusão, ela precisou da validação de sua resposta pelo tutor e, por isso, respondeu em forma de questão para também confirmar suas respostas.

Nessas duas situações, tutor e professoras, por meio do diálogo, mantiveram uma interação muito próxima e intensa, de forma tal que o primeiro conseguiu levá-las à reflexão sobre o episódio em questão e auxiliá-las para que construíssem seus conhecimentos, o que, segundo Borba, Malheiros e Zulatto (2007), faz a diferença na qualidade da aprendizagem.

\section{Algumas considerações}

Neste artigo, tivemos como objetivo discutir sobre algumas características - autonomia, interação, diálogo e colaboração - do curso de Pedagogia a distância da UAB-UFSCar, a partir de situações ocorridas nas disciplinas relacionadas à matemática.

As situações analisadas destacaram diversos aspectos que se relacionam às características discutidas.

A interação, colaboração e negociação efetiva que ocorreu na construção de textos coletivos, possibilitaram o compartilhamento de ideias, de experiências e o estabelecimento de uma confiança mútua entre os membros dos grupos, sem a qual não haveria a negociação para a escrita do texto, sendo que cada um apresentaria suas ideias sem uma discussão de quais eram ou não adequadas ao tema da atividade.

O modelo de curso a distância também promoveu o diálogo e a interação na perspectiva do estar junto virtual entre o professor responsável pelas disciplinas, os tutores e as professoras, de forma a essas últimas tornarem-se protagonistas no seu próprio processo de construção do conhecimento. Essa forma de interação e de diálogo possibilitou que todos os atores envolvidos participassem dos fóruns de discussão, professores e tutores tirassem dúvidas e dessem feedbacks das atividades realizadas, permitindo a construção de uma relação de respeito. Assim, não havia mais a hierarquia na qual professores e tutores são os detentores do conhecimento e os estudantes receptores de informações, mas tornaram-se parceiros no processo de ensino e de aprendizagem, em que todos ensinam e também aprendem.

Além disso, a colaboração entre as professoras e as demais colegas do curso, ao enviarem sugestões de sites, atividades, estratégias de resolução etc., foi importante para o desenvolvimento da autonomia. A colaboração entre os professores de uma escola é fundamental e seu desenvolvimento pode ser iniciado já na formação docente.

A mediação na $\mathrm{EaD}$ pode ter promovido o desenvolvimento da aprendizagem autônoma, pois a autonomia se dá de forma individual e na relação com o outro. As professoras colocaram-se em uma posição ativa nas situações destacadas e foram orientadas quanto ao caminho a ser seguido, a fim de construírem seus próprios conhecimentos. Não lhes foram dadas respostas prontas.

Assim, ao colocarem, nos fóruns, dúvidas ou questionamentos, elas proporcionaram tanto suas aprendizagens como também as dos colegas, e, muitas vezes, foram os próprios estudantes que trouxeram contribuições para sanar essas dúvidas, ao proporem reflexões, ao discordarem, ao concordarem, ao expressarem suas compreensões a partir dos comentários das participantes desta investigação.

Segundo Palloff e Pratt (2007), elaborar argumentos para confrontar pontos de vista exige um pensamento mais aprofundado, que ocorre apenas quando há a colaboração entre os atores envolvidos, pois essa atitude, que pode ser percebida nas situações discutidas, exige confiança, respeito mútuo e aceitação das opiniões iguais ou diferentes.

Assim, a qualidade do diálogo foi fundamental para essas aprendizagens e, por isso, destacamos que não pode haver o rompimento de um processo de comunicação, pois, como evidenciado também por Palloff e Pratt (2007), ele pode apresentar 
possibilidades positivas, ao permitir uma reflexão mais profunda dos comentários.

Podemos inferir que a exigência de trocas, de diálogos e de interação para a construção do conhecimento e da autonomia das professoras ocorreu nas disciplinas referentes à matemática.

Compreendemos ainda que a interação proposta, e que, de fato, ocorreu no curso, está de acordo com o estar junto virtual, pois buscou-se acompanhamento e assessoramento bem próximo aos estudantes. O tutor virtual, agente dessa interação, foi quem auxiliou na compreensão das dúvidas com relação aos conteúdos, na realização das atividades, no suporte necessário para que professoras desenvolvessem e aprendessem os conteúdos da disciplina.
Esses aspectos auxiliaram a manter a motivação das professoras, que estavam envolvidas em processos ativos, efetivos, que inspiraram confiança. Se na educação presencial o envolvimento é complicado, que dirá na EaD? Os cursos dessa natureza, que se limitam à transmissão de informação, de conteúdo, correm o risco da desmotivação e, principalmente, da aprendizagem por memorização, insuficiente para dar conta da complexidade e da relação teoria-prática de uma sala de aula.

Assim, podemos afirmar que as situações apresentadas e discutidas evidenciaram a autonomia, a interação, o diálogo e a colaboração por parte dos envolvidos nas disciplinas de matemática do curso de Pedagogia da UAB-UFSCar.

\section{REFERÊNCIAS}

ALRØ, Helle; SKOVSMOSE, Ole. Diálogo e aprendizagem em educação matemática. Tradução de O. Figueiredo. Belo Horizonte: Autêntica, 2006.

BARDIN, Laurence. Análise do conteúdo. Lisboa: Edições 70, 1977.

BATISTA, Erlinda M.; GOBARA, Shirley T. O fórum on-line e a interação em um curso a distância. 2007. Disponível em: <http://www.cinted.ufrgs.br/ciclo9/artigos/8cErlinda.pdf>. Acesso em: 08 out. 2012.

BELLONI, Maria L. Educação a Distância. Campinas, SP: Autores Associados, 2003.

BOGDAN, Robert C.; BIKLEN, Sari K. Investigação qualitativa em educação: uma introdução à teoria e aos métodos. Porto: Porto Editora, 1994.

BORBA, Marcelo C.; MALHEIROS, Ana P. S.; ZULATTO, Rúbia B. A. Educação a distância online. Belo Horizonte: Autêntica, 2007.

CARNEIRO, Reginaldo F. Processos formativos em matemática de alunas-professoras dos anos iniciais em um curso a distância de pedagogia. 2012. 308 f. Tese (Doutorado em Educação) - Centro de Educação e Ciências Humanas, Universidade Federal de São Carlos, São Carlos, 2012.

FIORENTINI, Dario; LORENZATO, Sergio. Investigação em educação matemática: percursos teóricos e metodológicos. Campinas, SP: Autores Associados, 2006.

GIOLO, J. A Educação a distância e a formação de professores. Educação e Sociedade, Campinas, SP, v. 29, n. 105, p. 1211-1234, 2008.

LÜDKE, Menga; ANDRÉ, Marli E. D. A. Pesquisa em educação: abordagens qualitativas. São Paulo: EPU, 1986.

MILL, Daniel. et al. O desafio de uma interação de qualidade na Educação a Distância: o tutor e sua importância nesse processo. Cadernos de Pedagogia, São Carlos, SP, v. 2, n. 4, p. 112-127, 2008. Disponível em: <http://www. cadernosdapedagogia.ufscar.br/index.php/cp/article/viewFile/106/63>. Acesso em: 10 set. 2012.

MOON, Bob. O papel das novas tecnologias da comunicação e da educação a distância para responder à crise global na oferta e formação de professores: uma análise da experiência de pesquisa e desenvolvimento. Educação e Sociedade, Campinas, SP, v. 29, n. 104, p. 791-814, 2008.

NOTARI, Michele. How to use a wiki in Education: wiki based effective constructive learning. In: INTERNATIONAL SYMPOSIUM ON WIKIS, 2006, Odense - Dinamarca. Anais... Odense - Dinamarca, 2006, p. 131-132. Disponível em: <http://www.wikisym.org/ws2006/>. Acesso em: 09 nov. 2012. 
PALLOFF, Rena M.; PRATT, Keith. Building online learning communities: effective strategies for the virtual classroom. San Francisco: Jossey-bass, 2007.

PRETI, Oreste. A “autonomia" do estudante na educação a distância: entre concepções, desejos, normatizações e práticas. In: $109-151$ (Org.). Educação a distância: sobre discursos e práticas. Brasília, DF: Líber Livro, 2005. p.

TANCREDI, Regina M. S. P.; REALI, Aline M. M. R.; MIZUKAMI, Maria G. N. Programa de mentoria para professores das séries iniciais: implementando e avaliando um continuo de aprendizagem docente. Relatório de pesquisa/FAPESP. São Carlos: DME/PPGE/UFSCar, 2005.

VALENTE, José A. Educação a distância no ensino superior: soluções e flexibilizações. Interface - Comunicação, Saúde, Educação, Botucatu, SP, v. 7, n. 12, p. 139-142, 2003.

Educação a distância: criando abordagens educacionais que possibilitem a construção de conhecimento. In: ARANTES, Valéria A. Educação a distância. São Paulo: Summus. 2011. p. 13-44.

Recebido em: 20.06.2015

Aprovado em: 20.09.2015 